\title{
Variation on Male Mating Success to Short-Term High Thermal Stress among Three Geographical Strains of Drosophila melanogaster
}

\author{
Banu Sebnem ÖNDER \\ Hacettepe University, Faculty of Science \\ Department of Biology, Ankara 06800, Turkey \\ Tel: 90-312-297-6291Ｅ-mail: bdalgic@hacettepe.edu.tr
}

\begin{abstract}
The effect of high temperature stress on mating success is investigated in three natural populations of Drosophila melanogaster from different geographical origins. In this experiment, the males of the control group were continuously kept at $25^{\circ} \mathrm{C}$ while the males of the second and third groups were kept at $36^{\circ} \mathrm{C}$ and $38.5^{\circ} \mathrm{C}$ respectively for $1 \mathrm{~h}$ before mating to evaluate the male mating success. One group of males exposed to short-term high thermal stress were immediately put into the vials to mate with females, while males of the second group were kept in the vials for a relaxation period for $1 \mathrm{~h}$ before mating. I found that mating success which was measured as the number of offsprings was higher in the group which was mated immediately after short-term high thermal stress. Also it is seen that the individuals exposed to $38.5^{\circ} \mathrm{C}$ were much more successful than the individuals which were kept at $25^{\circ} \mathrm{C}$. There is also some variation between the populations of different origins as a respond to thermal stress. This results show us that genotype environment interaction is higher for male mating success and the relaxation period after short-term thermal stress has a negative effect on male mating success.
\end{abstract}

Keywords: Heat-shock response, Male mating success, Relaxation period, Drosophila melanogaster

\section{Introduction}

Temperature is one of the most important environmental factors which have effects on some life history traits in ectotherms. It is well known that temperature is affecting many life history traits in Drosophila such as viability and reproduction (David, Allemand, Herrewege \& Cohet, 1983). Many physiological changes occur as temperature rises (Feder, 1996). High-temperature stress affects organisms in a variety of ways, and therefore the variation underlying this tolerance should depend upon how tolerance to stress is measured (Bennett, 1987; Hoffmann, Dagher, Hercus \& Berrigan 1997; Shine, Harlow, Elphick, Olsson \& Mason, 2000; Sørensen, Dahlgaard \& Loeschcke, 2001). Thermal stress, for example, can lead to shifts in the genetic and/or phenotypic correlations between life-history traits (Krebs \& Loeschcke, 1999). Consequences to fitness after heat stress may progress from a decline in oviposition and fertility, reduction in body size, a failure to mate, the cessation of locomotion (knockdown) and increased mortality (Feder \& Krebs, 1997; Fasolo \& Krebs, 2004).

In addition, there are some evidences that responds to high temperature stress vary among Drosophila melanogaster natural populations and this variation is probably the consequence of the populations being from different genetic backgrounds (Parsons, 1973). Surely, it can be said that mating success is one of the most important component of fitness when compared with the other fitness components (Fulker, 1966; Prout, 1971; Parsons, 1973). In addition, evidences that show the importance of mating success of males in wild Drosophila melanogaster populations are already exist (Anderson et al., 1979; Brittnacher, 1981). These results are also supported by other field examples from other groups of insects and vertebrates (Trivers, 1972; Parsons, 1997). In another study, Prout (1971) found that male mating success was much more important than female fecundity while comparing the fitness components in Drosophila melanogaster populations.

For species using habitats which fluctuate in temperature, resistance to thermal extremes may be closely related to fitness (Krebs \& Loeschcke, 1994a). How much genetic variation for temperature resistance is present in these 
populations is important with respect to any evolutionary responses associated with colonization of new environments (Hoffmann \& Parsons, 1991).

Possible mechanisms for variation in heat stress resistance are genetic variation in heat shock proteins, their regulation or in the thermal stability of structural and enzymatic proteins necessary for cell function (Morrison \& Milkman, 1978; Martin, Horwich \& Hartl, 1992). According to the results of the previous studies, very small quantity of induced heat shock proteins may affect life history traits such as development, stress resistance, life span and fecundity (Silbermann \& Tatar 2000; Patton \& Krebs, 2001; Sorensen et al., 2003; Sisodia \& Singh, 2006;). The presence of genetic variation without pre-treatment, is best explained by variation for non-stress quantities of those proteins that are mass produced in the presence of a stress, or by differences in the activation temperatures for the rapid transcription of these proteins (Krebs \& Loeschcke, 1994b). Beside, Bourg et al. (2001) studied the hsp70 protein expression exposed to 45-minutes long heat shock at $37^{\circ} \mathrm{C} .0,1,2,4,6,8$ and 12 hours later they measured the expression consecutively. The results showed that hsp70 expression increased significantly 4 hours after the heat stress. It can thus be concluded that the time after heat shock is important for heat shock protein expression.

In the scope of this study, I tested whether male mating success is affected under thermal stress conditions. I applied a comparative approach to assess why different populations of one species may vary in their response to different stress conditions. I chose high but non-lethal temperature regimes $\left(36^{\circ} \mathrm{C}\right.$ for $1 \mathrm{~h}$ and $38,5^{\circ} \mathrm{C}$ for $\left.1 \mathrm{~h}\right)$ for this purpose. These temperature conditions are known to be very high and act as a stress source for $D$. melanogaster. In addition, flies mating immediately after heat shock and flies mating after a $1 \mathrm{~h}$ relaxation period in $25^{\circ} \mathrm{C}$ were compared to find out the effect of relaxation after heat shock.

I asked four additional questions in this study using three natural populations of D. melanogaster, (1) Does mating success vary among populations? (2) Will mating success decrease as a consequence of inhibition of male mating ability after males are exposed to high temperatures? (3) How does relaxation period affect the organisms exposed to thermal stress?

\section{Material and methods}

The flies were collected between June-August 2002 at Ankara (39 $\left.57^{\prime} \mathrm{S}, 32^{\circ} 52^{\prime} \mathrm{W}\right)$, Giresun (40 $\left.55^{\prime} \mathrm{S}, 38^{\circ} 25^{\prime} \mathrm{W}\right)$ and Kerpe - Izmit $\left(41^{\circ} 13^{\prime} \mathrm{S}, 30^{\circ} 20^{\prime} \mathrm{W}\right)$, Turkey. These sampling sites are almost similar in some climatic parameters important for Drosophila development and habitation, for example total yearly values of rainfall $\left(\mathrm{R}_{\text {year }}\right)$, temperature $\left(\mathrm{T}_{\text {year }}\right)$ and humidity $\left(\mathrm{H}_{\text {year }}\right)$ (Table 1$)$. Table 1 shows climatic data and sample size for the population. After sampling in wild, flies were brought to laboratory and the lines had been maintained in standard corn meal Drosophila medium (Bozcuk, 1978) at $25^{\circ} \mathrm{C} \pm 1^{\circ} \mathrm{C}, 60 \%$ R.H. in population cage culture.

\section{Table 1}

Twenty pairs of flies were taken from each population and brown stock to be the parents of the experimental flies and were transferred to laying pots containing yeasted corn meal medium. After an acclimatory period of $24 \mathrm{~h}$ at $25^{\circ} \mathrm{C}$ the flies were transferred to fresh medium for a $2 \mathrm{~h}$ pre-lay period and then transferred again to fresh medium for $4 \mathrm{~h}$ at $25^{\circ} \mathrm{C}$ for egg collection. Eggs were collected $4 \mathrm{~h}$ after the midpoint of lay. Fifty eggs were placed in vials containing 7 $\mathrm{mL}$ medium, with five vials per natural population and ten vials for brown stock. Collection of unmated emerging flies from these vials was carried out by anesthesia with ether within $8 \mathrm{~h}$ of eclosion.

\subsection{Measurement of male mating success}

The high thermal stress applied to unmated males from the natural populations exposure for $1 \mathrm{~h}$ in an incubator set to $36^{\circ} \mathrm{C}$ and $38,5^{\circ} \mathrm{C}$.

Mating success was compared among males in three natural population and in three treatment groups: 1- untreated $\left(25^{\circ} \mathrm{C}\right) ; 2$ - treated at $36^{\circ} \mathrm{C}$ for $1 \mathrm{~h} ; 3$ - treated at $38.5^{\circ} \mathrm{C}$ for $1 \mathrm{~h}$. All groups are carrying out in two way; $1-$ mating occurs behind a $1 \mathrm{~h}$ relaxation period, 2 - mating occurs with out a relaxation period after the thermal stress.

Mating success analyses were performed using the same protocol of Reeve et al. (2000). At each temperature, for each population, 10 virgin brown females, three wild type males, and seven brown males were set up in each of 10 replicate vials, each containing $7 \mathrm{~mL}$ of food medium and active yeast. This design ensured that the wild type males competed mainly with brown males, rather than with each other. Two hours later, adult flies were removed from the vials. Because long mating period may prevent us to observe the putative effects of the relaxation period.

The brown eye color recessive mutant marker stock used as a competitor stock. Crosses between wild type males (red eye) and males and females of brown mutant (brown eye) were conducted. To provide an estimate of male mating success for each population the phenotypes of progenies were recorded. In all crosses only the red eye phenotype numbers were counted from each vial after 15 days. Figure 1 summarizes the percentage of progeny for three populations, in all temperatures with and without relaxation period.

\section{Figure 1}




\subsection{Statistical analysis}

Univariate analysis of variance (ANOVA) provides an extremely powerful and useful tool for statistical tests of factors and their interactions in experiments (Underwood 1981, 1997). The ANOVA procedure is robust with respect to deviations from normality. The normality assumption was tested by Shapiro-Wilk test $(\mathrm{p}<0.05)$ and the assumption of heterogeneity of variances was tested by Levene's test $(p<0.05)$. These tests showed that the assumptions were not satisfied. The raw data on number of offspring was logarithmic transformed to ensure normality and homogeneity of variances before subjecting to statistical analysis.

\section{Results}

The significance of the effect of temperature, population and relaxation period on the number of offspring was analyzed using a three-way analysis of variance (ANOVA), in which temperature $\left(25^{\circ} \mathrm{C}, 36^{\circ} \mathrm{C}, 38.5^{\circ} \mathrm{C}\right.$ ), population (Giresun, Ankara, Kerpe) and relaxation period (1 - mating occurs after a $1 \mathrm{~h}$ relaxation period, 2 - mating occurs with out a relaxation period after the thermal stress), constituted the three factors in the analysis. When significant effects of temperature were established $(\mathrm{F}=27.411, \mathrm{df}=2, \mathrm{p}<0.05)$, differences among temperatures were tested using Dunnett's test and also when significant effects of population were established $\quad(\mathrm{F}=48.242, \mathrm{df}=2, \mathrm{p}<0.05)$, differences among populations were tested using Student-Newman-Keuls test. Dunnett's test exposed that the temperature $36^{\circ} \mathrm{C}$ differed significantly from the control group whereas the temperature $38.5^{\circ} \mathrm{C}$ didn't differ from the control group and Student-Newman-Keuls multiple comparison test exposed that all types of population differed from each other $(\mathrm{p}<0.05)$. Significant differences were found between the groups of relaxation period $(\mathrm{F}=10.711, \mathrm{df}=1, \mathrm{p}<0.05)$.

The results of three-way analysis of variance (ANOVA) are presented in Table 2.

\section{Table 2}

\section{Discussion}

It is well known that Drosophila melanogaster shows numerous genetic differences between tropical and temperate populations (Trotta et al, 2006), but in my study there is not much temperature differences between collection sites of natural populations used in this experiment (Table 1). However, my results indicate some thermal stress response differences between populations although they are from similar temperature conditions. The common result for all populations is the negative effect of the relaxation period on mating success after thermal stress exposure.

Besides, comparison of $38.5^{\circ} \mathrm{C}$ treatment with $36^{\circ} \mathrm{C}$ treatment shows us that offspring number increases generally at $38.5^{\circ} \mathrm{C}$ treatment with or without a relaxation period. This increase especially can be seen in Ankara population as a 5 fold increase of the control group (Fig. 1). Male mating success effects were also large to high heat stress $\left(38.5^{\circ} \mathrm{C}\right)$, although offspring production of males that mated after a exposure of a lower heat stress $\left(36^{\circ} \mathrm{C}\right)$ was in general not less than that of unstressed males. However, in a similar examined by Krebs and Loeschcke (1994a) exposure to a short-term thermal extreme, is not effected reproductive output of males, although survival rate decrease by high thermal exposure. Additionally, Nishinokubi et al. (2006) found that mating rates of wild type Drosophila melanogaster adults increased slightly under short term heat shock $\left(37^{\circ} \mathrm{C}\right)$ in opposite to the unstressed flies. It is possible that an increase in temperature enhances the volatility of pheromones and therefore increases mating activity (Nishinokubi, Shimoda \& Ishida, 2006).

In contrast to my measures after exposed to a non-lethal high temperature at $38.5^{\circ} \mathrm{C}$, it was found that the number of offspring of males exposed to $36^{\circ} \mathrm{C}$ were lower than the control or almost similar to the control. Indeed, heat shock exposures, nearly the lethal ranges have a positive effect of male mating success (Krebs \& Loeschcke 1996).

The objective of my study is to reveal the possible differences between the mating successes of groups had a relaxation period and those did not. However, some of the previous studies tested the temperature effect on life history traits immediately after the stress and the others test its effect after a relaxation period (Krebs \& Loeschcke, 1994b; 1999; Patton \& Krebs, 2001; Fasolo \& Krebs, 2004; Krebs \& Thompson, 2005; Nishinokubi et al., 2006; Sisodia \& Singh, 2006). My data show that relaxation period had a negative effect of male mating success. Flies waited $1 \mathrm{~h}$ after the heat shock exposures were found to be unsuccessful when they were compared to the unstressed flies. However, the groups that mated immediately after the high thermal heat exposure - despite of Giresun population - were more successful in mating.

Heat shock protein expressions in D. melanogaster are increase through time after the temperature exposure and peak at 4 hours after heat stress (Nishinokubi et al., 2006). But is unclear how heat shock protein expressions lead to effect life history traits. Besides, heat shock protein levels after the heat shock and after the relaxation period were not studied. Further studies should be focused on the effects of heat shock exposure time variying 0 to 12 hours to explain the possible effects of heat shock protein expression on fitness components.

Global and local changes in climate are well documented (Permesan \& Galbraith, 2004). With increases in either the mean temperature or its variance, populations will more likely become exposed to short-term thermal stress, and the 
amount of genetic variation present within a population for stress resistance may be an indicator of how that population will adapt.

In conclusion, these three populations I examined showed different response to thermal stress. Thus, it gives me the idea that the different responses shown to environmental stresses may be related to the population's genetic background. However, although I did not find any relationships between the general climatic values and mating success, micro climatic conditions where populations originated should be evaluated in relation to this fitness component.

\section{Acknowledgement}

The author thanks Banu Arvas, Sevil Cevik, Irem Matur and Ekim Taskiran for their excellent technical assistance, Nihal Ata and Murat Yilmaz for his comments of the manuscript and Dr. Ergi Deniz Özsoy for his comment until the experimental design. I thank the reviewers for their contributions to improvement of the manuscript.

\section{References}

Anderson, W.W., Levine, L., Olvera, O., Powell, J.R., de la Rosa, M.E., Salceda, V.M., Gaso, M.I., Guzmán, J. (1979). Evidence for selection by male mating success in natural populations of Drosophila pseudoobscura. Proc Natl Acad Sci US A. Mar, 76(3), 1519-1523.

Bennet, A.F. (1987). Interindividual variability: an underutilized resource. In Feder, M.E., Bennet, A.F., Burggren, W.W., Huey, R.B. (Eds.), New directions in ecological physiology (pp. 147-165). Cambridge: Cambridge University Press.

Brittnacher, J. G. (1981). Genetic variation and genetic load due to the male reproductive component of fitness in Drosophila. Genetics 97, 719-730.

Bourg, E.L., Valenti, P., Lucchetta, P., Payre, F. (2001). Effects of mild heat shocks at young age on aging and longevity in Drosophila melanogaster, Biogerontology, 2, 155-164.

Bozcuk, A.N. (1978). The effects of some genotypes on longevity of adult Drosophila. Exp. Gerontology, 13, $279-286$.

David, J.R, Allemand, R., Van Herrewege, J. \& Cohet, Y. (1983). Ecophysiologie: abiotic factors. In: M. Ashburner, H.L. Carson and J.N. Thompson, (Eds.) Genetics and biology of Drosophila (pp. 105-170) Academic Press, New York.

Fasolo, A.G. \& Krebs, R.A. (2004). A comparison of behavioural change in Drosophila during exposure to thermal stress, Biological Journal of the Linnean Society, 83, 197-205.

Feder, M. E. (1996). Ecological and evolutionary physiology of stress proteins and the stress response: The Drosophila melanogaster model. In I. A. Johnston, A. F. Bennett (Eds.), Animals and tem-perature: Phenotypic and evolutionary adaptation (79-102). Cambridge University Press, Cambridge, U.K.

Feder, M.E. \& Krebs. R.A. (1997). Ecological and evolutionary physiology of heat-shock proteins and the stress response in Drosophila: complementary insights from genetic engineering and natural variation. In Bijlsma, R. \& Loeschcke, V. (Eds.), Stress, Adaptation, and Evolution (pp. 155-173). Birkhuser Verlag, Basel.

Fulker D.W. (1966). Mating speed in male Drosophila melanogaster: A psychogenetic analysis. Science 153, $203-205$.

Hoffmann, A.A. \& Parsons, P.A. (1991). Evolutionary Genetics and Environmental Stress. Oxford Science Publications, Oxford.

Hoffmann, A.A., Dagher, H., Hercus, M., Berrigan, D. (1997). Comparing different measures of heat resistance in selected lines of Drosophila melanogaster. Journal of Insect Physiology 43, 393-405.

Krebs, R. A. \& Loeschcke, V. (1994a). Costs and benefits of activation of the heat shock response in Drosophila melanogaster. Funct. Ecol. 8, 730-737.

Krebs, R. A. \& Loeschcke, V. (1994b). Effects of exposure to short-term heat stress on fitness components in Drosophila melanogaster. J. Evol. Biol. 7, 39-49.

Krebs, R.A. \& Loeschcke, V. (1996). Acclimation and Selection for increased resistance and acclimation to thermal stress in Drosophila buzzatii. Genetics 142, 471-479.

Krebs, R. A. \& Loeschcke, V. (1999). A genetic analysis of the relationship between life-history variation and heat-shock tolerance in Drosophila buzzatii. Heredity 83, 46-53.

Krebs, R.A. \& Thompson, K.A. (2005). A genetic analysis of variation for the ability to fly after exposure to thermal stress in Drosophila mojavensis, Journal of Thermal Biology 30, 335-342.

Martin, J., Horwich, A.L., Hartl, F.U. (1992). Prevention of protein denaturation under heat stress by the Chaperonin Hsp60. Science, 58, 995-998. 
Morrison, W.W. \& Milkman, R. (1978). Modification of heat resistance in Drosophila by selection, Nature, 273, 49-50.

Nishinokubi, I., Shimoda, M., Ishida, N. (2006). Mating rhythms of Drosophila: rescue of tim $^{01}$ mutants by $D$. ananassae timeless. Journal of Circadian Rhythms, $4,4$.

Parmesan, C. \& Galbraith, H. (2004). Observed Ecological Impacts of Climate Change in North America. Arlington, VA: Pew Cent. Glob. Clim. Change.

Parsons, P. A. (1973). Genetics of resistance to environmental stresses in Drosophila populations. Annu. Rev. Genet .7, 239-265.

Parsons, P.A. (1997). Success in mating: a coordinated approach to fitness through genotypes incorporating genes for stress resistance and heterozygous advantage under stress. Behavior Genetics, 27 (1), 75-81.

Patton, Z.J. \& Krebs, R.A. (2001). The effect of thermal stres on the mating behaviour of three Drosophila species, Physiological and Biochemical Zoology, 74(6), 783-788.

Prout, T. (1971). The relation between fitness components and population prediction in Drosophila. I. The estimation of fitness components. Genetics 68, 127-149.

Reeve, M.W., Fowler, K., Partridge, L. (2000). Increased body size confers greater fitness at lower experimental temperature in male Drosophila melanogaster. J. Evol. Biol. 13, 836-844.

Shine, R., Harlow, P.S., Elphick, M.J., Olsson, M.M. \& Mason, R.T. (2000). Conflicts between courtship and thermoregulation: the thermal ecology of amorous male garter snakes (Thamnophilis sirtalis parietalis, Colubridae), Physiol. Biochem. Zool. 73, 508-513.

Silbermann, R., Tatar, M. (2000). Reproductive costs of transgenic hsp70 overexpression in Drosophila. Evolution, 54, 2038-2045.

Sisodia, S. \& Singh, B. N. (2006). Effect of exposure to short-term heat stress on survival and fecundity in Drosophila ananassae. Can. J. Zool., 84, 895-899.

Sørensen, J.G., Dahlgaard, J., Loeschcke, V. (2001). Genetic variation in thermal tolerance among natural populations of Drosophila buzzatii: down regulation of $\mathrm{Hsp} 70$ expression and variation in heat stress resistance. Functional Ecology 15, 289-296.

Sørensen, J.G., Kristensen, T.N., Loeschcke, V. (2003). The evolutionary and ecological role of heat shock proteins. Ecology Letters 6, 1025-1037.

Trivers, R.L. (1972). Parental investment and sexual selection. In B. Campbell (Ed.), Sexual selection and the descent of man, 1871-1971 (pp. 136-179). Chicago, IL: Aldine.

Trotta, V., Calboli, F.C.F., Ziosi, M., Guerra, D., Pezzoli, M.C., David, J.R., Cavicchi, S. (2006). Thermal plasticity in Drosophila melanogaster: a comparison of geographic populations. BMC Evol. Biol. 6, 67.

Underwood, A. J. (1981). Techniques of analysis of variance in experimental marine biology and ecology. Ann. Rev. Oceanogr. Mar. Biol 19, 513-605.

Underwood, A. J. (1997). Experiments in ecology: their logical design and interpretation using analysis of variance. Cambridge, UK: Cambridge University Press.

Table 1. Population of the study with respect to some biogeographical parameters

\begin{tabular}{cccccccc}
\hline Population & Latitude & Altitude $(\mathrm{m})$ & $R_{\text {year }}(\mathrm{mm})$ & $H_{\text {year }}(\%)$ & $T_{\text {year }}\left({ }^{\circ} \mathrm{C}\right)$ & $T_{\max }\left({ }^{\circ} \mathrm{C}\right)$ & $T_{\min }\left({ }^{\circ} \mathrm{C}\right)$ \\
\hline Ankara & $39^{\circ} 57^{\prime}$ & 843 & 378 & 60 & 11,83 & 17,63 & 6,34 \\
Giresun & $41^{\circ} 13^{\prime}$ & 10 & 1294 & 77 & 14,41 & 17,69 & 11,83 \\
Kerpe & $40^{\circ} 55^{\prime}$ & 2 & 785 & 67 & 14,60 & 19,39 & 10,83 \\
\hline
\end{tabular}

$R_{\text {year: }}$ average yearly rainfall; $H_{\text {year }}$ : average yearly humidity; $T_{\text {year }}$ : average yearly temperature; $T_{\text {max }}$ : average yearly maximum temperature; $T_{\min }$ : average yearly minimum temperature. 
Table 2. The results of three-way analysis of variance

\begin{tabular}{l|llll}
\hline Effect & $\boldsymbol{M S}$ & $\boldsymbol{d} . \boldsymbol{f}$. & $\boldsymbol{F - \text { ratio }}$ & $\boldsymbol{p}$ \\
\hline Corrected Model & 38.770 & 17 & 16.623 & 0.000 \\
Temperature & 69.948 & 2 & 509.836 & 0.000 \\
Relaxation period & 7.522 & 1 & 27.411 & 0.000 \\
Population & 1.469 & 2 & 10.711 & 0.001 \\
Temperature*Relaxation period & 0.869 & 2 & 48.242 & 0.000 \\
Temperature*Population & 3.884 & 4 & 3.166 & 0.045 \\
Relaxation period*Population & 1.527 & 2 & 7.077 & 0.000 \\
Temperature*Relaxation & 3.659 & 4 & 5.564 & 0.005 \\
period*Population & & & & \\
Error & 18.384 & 134 & 6.667 & 0.000 \\
Total & 136.584 & 152 & & \\
\hline Corrected Total & 57.154 & 151 & & \\
\hline
\end{tabular}

$M S=$ mean square; d.f. = degrees of freedom

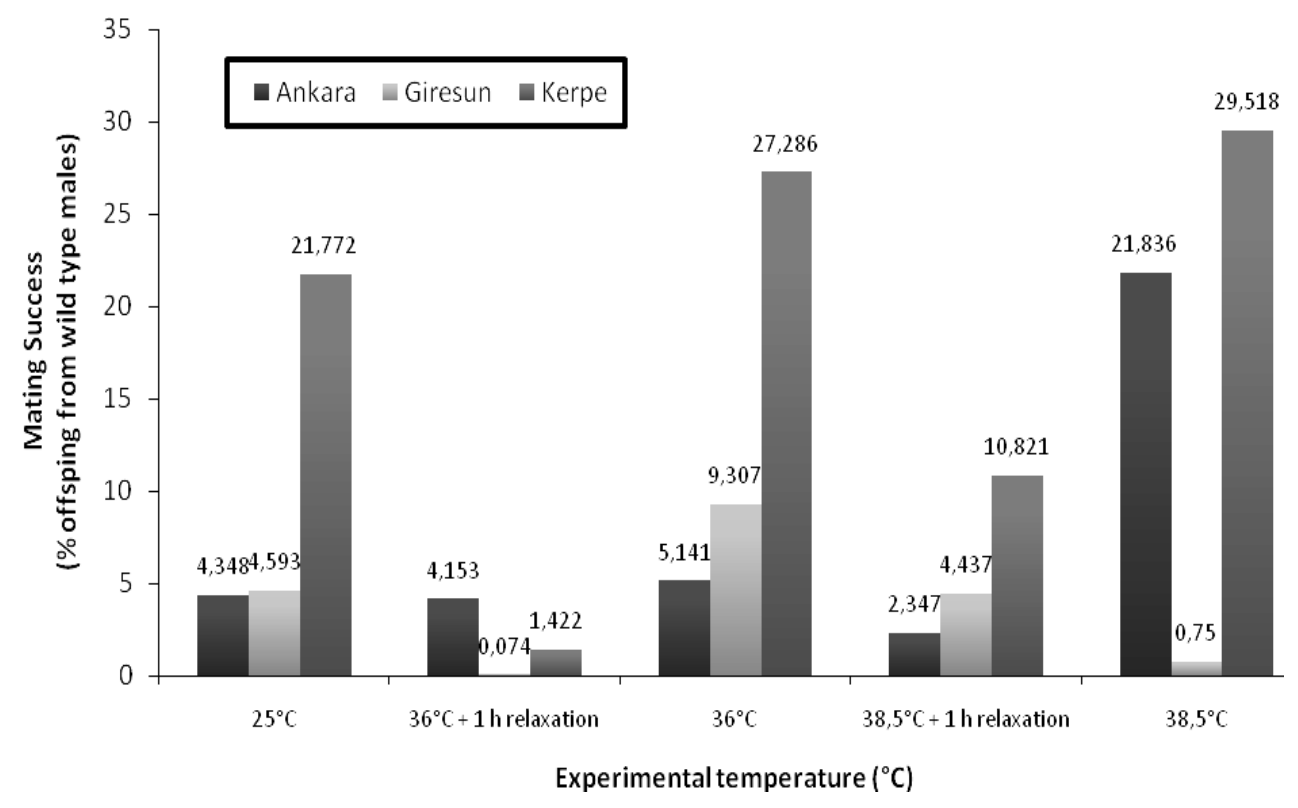

Figure 1. The percentage of progeny for three populations, in all temperatures with and without relaxation period 